\title{
Manuais de história da educação: da produção de conhecimento à disseminação de saberes escolares ${ }^{1}$ (1990-2009)
}

\author{
Maria Lourdes Silva* \\ Gisele dos Santos Oliveira
}

\section{Resumo}

Este trabalho problematiza a reiterada publicação de um manual de história da educação brasileiro. Para tanto, coteja-se a primeira edição (1990), intitulada História da educação, com a recente versão, reeditada pela quarta vez em 2009, publicada sob o título História da educação brasileira, de Paulo Ghiraldelli Jr. O recorte temporal observa exercício historiográfico dos dois momentos editoriais, os quais se constituem nos documentos acerca do debate sobre a prevalência dos saberes em disputa no campo da história da educação. Objetiva-se refletir sobre as seguintes questões, à luz dos endereçamentos para essa produção e das suas condições específicas de escrita/reescrita: a malha institucional onde se inscreveu/inscreve, o campo de saberes que legitima, o apagamento das representações em disputa e os significados da circulação dessa obra para o campo da história da educação.

Palavras-chave: História da educação. Paulo Ghiraldelli Jr. Historiografia.

\section{Introdução}

Este trabalho procurou problematizar a reiterada publicação de um manual de história da educação brasileiro desde a primeira edição, em 1990, até sua mais recente versão, reeditada, em 2009, pela quarta vez. ${ }^{2}$ Faz-se o recorte, portanto, privilegiando o exercício historiográfico no qual os manuais intitulados, respectivamente, História da educação, em sua primeira versão, e História da educação brasileira, na versão mais recente, do professor Paulo Ghiraldelli Jr. Esses manuais constituem os documentos a partir dos quais nós enfatizamos aspectos do debate que envolve ações políticas agenciadas por instituições diversas, interessadas em fazer prevalecer saberes em disputa no campo da história da educação.

Recebido: 05/06/2013 - Aprovado: 23/06/2013

http://dx.doi.org/10.5335/rep.2013.3560

Professora Adjunta da Faculdade de Educação da Universidade do Estado do Rio de Janeiro, área de História da Educação. E-mail: lullua2@yahoo.com.br.

Mestranda no PROPEd-UERJ. E-mail: giselefloquinho@yahoo.com.br 
Em texto recente, Miriam Warde (2011) faz importante reflexão sobre os rumos do ensino e da pesquisa em história da educação, considerando aspectos formadores dos quadros da área nos últimos vinte anos. Analisando variáveis tais como procedência da formação na graduação, investimentos em pesquisas e temas privilegiados particulares e institucionais, além da distribuição desses quadros nas Instituições de Ensino Superior no país, dentre outros, a autora indaga sobre o perfil dos docentes de história da educação formados nos programas de pós-graduação espalhados pelo país, relacionando quesitos como relações entre orientadores e orientandos, redes de interação institucionais, intelectuais ou pessoais e, sobretudo, problematizando a relação entre a produção do campo e sua disseminação através do ensino dessa mesma disciplina. Considera necessário pensar sobre os mecanismos de formação, agenciamento e associação dos docentes/pesquisadores/ autores de história da educação no esforço de compreender os meios pelos quais se forjam as relações elencadas.

Caminhando na reflexão, ela desemboca numa instigante análise acerca das possibilidades de renovação dos quadros docentes da área e, consequentemente, da produção desta com base nos indicadores da tendência atual das políticas para o ensino da graduação e da pós-graduação. Acerca do respeitável volume da produção da área, afirma:

Enquanto têm sido alardeadas as mudanças na História da Educação, quer em relação ao volume, quer em relação às características das suas pesquisas e publicações, pouco se comenta a respeito das condições de seu ensino, isto é, pouco se sabe se, com referência a esse aspecto, a disciplina estaria sofrendo mudanças em consequência da utilização em sala de aula das novas descobertas e da circulação de novos trabalhos. Mas não só por isso, como também e principalmente pelas transformações que teriam ocorrido no perfil dos professores responsáveis pela disciplina nos cursos em que é oferecida regularmente (WARDE, 2011, p. 305-306).

Às problematizações apontadas pela autora, deve ser acrescida a reflexão de Gondra e Ascolani (2009), quando afirmam que pensar a educação como objeto de uma escrita de caráter histórico significa refletir sobre a expressão das vontades imperiosas na disposição de registro, memória e controle no processo dessa escrita. Não sem disputas e tensões, discursos são produzidos, postos em circulação, dados à apropriação por expedientes tais como os manuais de orientação didática, a um só tempo, teórico, metodológico e temático. Tais manuais constituem-se em guias, cuja função disciplinar opera mediante constrangimentos, limitações, ausências e silêncios em que o papel precípuo dessa disciplina da área de fundamentos da educação cumpre atribuições normativas. 
Considerando esse diagnóstico, este trabalho procurou analisar a publicação dos manuais de história de educação referidos em sua primeira edição, em 1990, e uma edição da recente versão, a que foi reeditada, em 2009, pela quarta vez. ${ }^{3}$ Procuramos observar as seguintes questões à luz dos endereçamentos possíveis para essa produção e das condições específicas que forjaram sua escrita/reescrita: 1) a malha institucional onde se inscreveram/inscrevem esses manuais; 2) os enunciados constituídos no conjunto de sua escrita, atentando para as implicações do apagamento das discussões em curso e das representações em disputa nesse campo do conhecimento; 3) o campo de saberes que eles arregimentam, reforçam e legitimam; 4) os significados da circulação dessa obra para o campo da história da educação.

Nos limites deste trabalho, nos contentaremos em proferir considerações gerais sobre a apresentação e o capítulo I da versão primeira do livro, de 1990; mais a introdução, os capítulos 1, 2 e 3 da versão atualizada, edição de 2009 (ver quadro dos capítulos ao final do texto).

\section{Os embates do campo editorial}

A primeira versão do manual, publicada pela editora Cortez como parte da "Coleção magistério - $2^{\circ}$ Grau", estava dividida em duas séries: "Série formação geral”, com 12 títulos, sendo um para cada disciplina do núcleo comum do $2^{\circ}$ grau, e a "Série formação do professor", sendo um para cada disciplina da formação profissional para o magistério no ensino de $1^{\circ}$ grau, segundo consta na "Apresentação" da coleção na abertura dessa primeira edição, onde a editora assim a descreve: "a coleção é formada de 25 livros didáticos para uso do professor e alunos do ensino de $2^{\circ}$ grau e da habilitação magistério, dos cursos de pedagogia e das licenciaturas" (GHIRALDELLI JR., 1990, p. 9). Quanto às finalidades da coleção, assim delibera:

[...] cada um dos livros oferece a professores e alunos, além dos textos referentes às unidades dos programas, um estudo sobre os objetivos da disciplina, uma proposta de conteúdos básicos e indicações metodológicas para o trabalho conjunto do professor e dos alunos, formas de articulação com as outras disciplinas e uma bibliografia complementar para aprofundamento de estudos (GHIRALDELLI JR., 1990, p. 9).

O livro em foco foi publicado nessa segunda série.

A nova versão do manual não pertence mais à coleção, já extinta. Na mesma editora, o livro é atualizado e lançado como título único, sem vínculo com qualquer coleção. ${ }^{4}$ A primeira edição data de 2006 e a quarta, com a qual trabalhamos, foi publicada em 2009. Isso corresponde a dizer que o livro teve quatro edições em três anos. Em que pese o número da tiragem de cada edição, ${ }^{5}$ infere-se que a publicação 
representa um sucesso editorial. Para tanto, contribuíram a força da editora tradicionalmente voltada para o campo educacional - com 16 coleções voltadas à área atualmente; a crescente representatividade do campo, sobretudo, no ensino voltado à formação de professores pela crescente demanda docente no que diz respeito à sua busca por preparo e aperfeiçoamento, aos investimentos institucionais diversos voltados a esse propósito ao conjunto dos quais a obra em foco atende enquanto bibliografia disponibilizada pelo campo da história da educação - seja pelos formadores desses docentes, seja pelo mercado editorial - aos programas dos cursos elaborados e promovidos por esse espaço acadêmico.

\section{0 lugar da autoria}

Paulo Ghiraldelli Jr. define-se como filósofo e escritor em seu blog, ${ }^{6}$ onde os mais diversos assuntos são postos em discussão, seguindo a tendência da filosofia atual. De todos esses envolvimentos e pertencimentos, fica a clara posição de um filósofo que adentra o campo da história da educação por sua porta mais tradicional, que não dissociava história da educação e filosofia como nas antigas cadeiras das Faculdades de Educação da Universidade de São Paulo (USP) e da Pontifícia Universidade Católica de São Paulo (PUC-SP).

Com graduação em Educação Física, o autor fez doutorado em Filosofia pela USP e doutorado em Filosofia da Educação pela PUC-SP. Realizou um primeiro mestrado em Filosofia pela USP e um segundo mestrado em Filosofia e História da Educação pela PUC-SP. Foi orientando de Maria Luiza Santos Ribeiro e Dermeval Saviani, tendo participado do grupo de estudos e pesquisas História, Sociedade e Educação no Brasil (HISTEDBR) coordenado por Saviani. Obteve sua livre-docência pela Universidade Estadual Paulista (Unesp), tornando-se professor titular. Tem, ainda, pós-doutorado na Universidade do Estado do Rio de Janeiro (UERJ) pelo Instituto de Medicina Social (IMS) e pós-doutorado em Medicina Social pela UERJ. Atualmente é professor da Universidade Federal Rural do Rio de Janeiro (UFRRJ). Participou da Associação Nacional de Pós-Graduação em Filosofia (ANPOF) e hoje dirige o Centro de Estudos em Filosofia Americana (CEFA), por ele fundado, em 1996, onde publica regularmente ensaios sobre a realidade nacional perspectivados pela filosofia - campo do conhecimento onde seus investimentos sugerem ter o professor estabelecido sua identidade profissional. 


\section{Uma leitura dentre as possíveis}

Na primeira versão do livro História da educação, de 1990, em sua apresentação, o autor define os dois significados da palavra "história": 1) processos de existência e vida real dos homens no tempo; 2) o relato estruturado desses processos humanos, o estudo científico. Destaca, ainda, o termo "historiografia" nas duas acepções que identifica: 1) o produto da investigação da ciência histórica; 2) o que designa a discussão que envolve a história da história. Partindo dessas definições, afirma que a história da educação carrega esse duplo sentido da palavra "história" aliado à reflexão teórica que, invariavelmente, acompanha a educação, o que, para ele, constitui a pedagogia. Isso implica compreender a história da educação como sendo, ao mesmo tempo, história da educação e da pedagogia, que deve ser vista em seus dois principais planos: 1) o das políticas educacionais, que envolve as relações entre o estado, a educação e a sociedade; 2 ) o das construções pedagógico-didáticas, que diz respeito ao trabalho prático e às teorizações das classes sociais quanto ao fazer pedagógico nas unidades escolares e educacionais. À luz dessa intenção, adverte que não teve o intuito de fazer um manual, mas um roteiro de estudos da matéria para os estudantes do curso de formação para o magistério centrado no desenvolvimento educacional e pedagógico do período republicano.

Segue-se, então, o tratamento dos capítulos organizados segundo a divisão temporal clássica da história da República brasileira (ver quadro no final do texto): capítulo I - A Primeira República; capítulo II - A Segunda República; capítulo III O Estado Novo; capítulo IV - A Quarta República; capítulo V - A Ditadura Militar; capítulo VI - A Ditadura Militar e o Advento da Nova República; Bibliografia. Ao final de cada capítulo, um conjunto breve de livros é indicado para leitura complementar e aprofundamento, seguido de exercícios propostos pelo autor. No interior de cada capítulo ou período, ele recupera as diferentes legislações sobre educação, as ideias pedagógicas em circulação e a efetiva organização do sistema escolar.

O primeiro capítulo dessa primeira edição abre-se indicando como observar a "evolução das ideias pedagógicas na Primeira República (1889-1930)" por meio da apreciação de dois movimentos feitos pelos intelectuais da classe dominante do país à época. O primeiro, o autor caracteriza-o como sendo o que denomina de "entusiasmo pela educação", pautado na expansão quantitativa da rede escolar, cujo fim era o de atingir a desanalfabetização do povo; o segundo denomina de "otimismo pedagógico", porque privilegiava a melhoria das condições didáticas e pedagógicas da rede escolar, ou o aspecto qualitativo da educação. O primeiro, conforme o autor, seria herança do Império; o segundo seria genuinamente republicano. Das mudanças do final do Império que ensejam a República, assim assinala a questão da educação: 
A reorganização do Estado devido ao advento da República, assim como a urbanização do país, forma fatores decisivos para a criação de novas necessidades para a população, o que possibilitou que a escolarização aparecesse como meta almejada pelas famílias que viam nas carreiras burocráticas e intelectuais um caminho mais promissor para seus filhos (GHIRALDELLI JR., 1990, p. 16).

Temas como democracia, federalismo, industrialização, educação popular (resumida à desanalfabetização da população) incitavam os intelectuais e grupos ligados ao Estado. Os problemas do país passavam pela educação do povo, mas as práticas excludentes do governo oligárquico da Primeira República sufocaram o entusiasmo até os anos 1910. Somente após a Grande Guerra, o surto nacionalista e patriótico repôs à cena o entusiasmo pela educação popular. O veículo do movimento foi expresso nas "ligas contra o analfabetismo", que desempenhavam um papel modernizador e consubstanciaram a luta entre a incipiente burguesia urbana e a política das oligarquias.

Esse entusiasmo teria sido diferente do início da República, pois caminhou por meio de entidades da sociedade civil, e não da sociedade política, como no momento anterior. A influência da pedagogia de John Dewey é presença destacada pelo autor nos debates dos anos 1920, assim como as influências da sociedade americana incidiam diretamente sobre o movimento da Escola Nova, coadunando-se às preocupações correntes em torno da reorganização interna das escolas e ao redirecionamento dos padrões didáticos e pedagógicos. Nos anos 1920, entusiasmo e otimismo confrontam-se e complementam-se nas Conferências Brasileiras de Educação promovidas pela Associação Brasileira de Educação (ABE). O debate sai do Congresso Nacional e vai para o âmbito da sociedade civil, dando o tom dos acontecimentos pós-Revolução de 1930 .

Nesse debate, identificam-se três correntes pedagógicas distintas: a pedagogia tradicional, a pedagogia nova e a pedagogia libertária. Diz que, grosso modo, essas pedagogias podem ser associadas a três setores sociais, respectivamente: aos intelectuais ligados às oligarquias e à Igreja; à burguesia e às classes médias urbanas; e aos intelectuais dos movimentos sociais populares (operário, anarquista e anarcossindicalista). Sobre o primeiro grupo, observa:

Boa parte do professorado na Primeira República, religioso ou leigo, tinha suas linhas pedagógicas dirigidas pelos princípios gerais do Ratio Studiorum. Um século depois da expulsão dos jesuítas do Brasil, ainda permanecia, incrustado na cabeça dos professores, um regrário didático com origem no Ratio, o que mostra, de certa forma, a incapacidade do pensamento laico em superar a organização da cultura forjada pelo catolicismo no Brasil (GHIRALDELLI JR., 1990, p. 20).

O capítulo segue demonstrando as características de cada corrente de pensamento educacional encontradas no Brasil de então, terminando com a pedagogia 
nova e a forma como ela se converte em reforma nos governos estaduais, unindo sociedade civil e política, pois era uma "forma de pensamento educacional completo, na medida em que compreendia uma política educacional, uma teoria da educação e de organização escolar e metodologias próprias" (GHIRALDELLI JR., 1990, p. 26). No final do primeiro capítulo, o autor dedica-se a descrever a organização escolar na Primeira República. E a esse respeito, declara:

Não havia uma rede de escolas públicas respeitável, e a que existia voltava-se para o atendimento das classes mais favorecidas economicamente [...] [a] Primeira República logrou a construção de um sistema de ensino pouco democrático que privilegiava o ensino secundário e superior em detrimento da expansão do ensino primário (GHIRALDELLI JR., 1990, p. 27).

Destacando as diferenças e particularidades do sistema educacional nacional em cada estado da federação, Ghiraldelli Jr. afirma que eles evoluíram segundo essas especificidades, mas toma o estado de São Paulo como "exemplo para o entendimento da vida escolar naqueles anos" (1990, p. 28). Nesse exemplo, ele se detém na descrição da organização do ensino primário oficial do estado dividido em curso preliminar e complementar.

O primeiro, laico e gratuito, destinado às crianças de 7 a 15 anos, raramente com permissão para funcionar em regime de coeducação, abrigava extenso currículo com as disciplinas:

Leitura; Escrita e Caligrafia; Moral Prática; Educação Cívica; Geografia Geral; Cosmografia; Geografia do Brasil; Noções de Física; Química e História Natural (Higiene); História do Brasil e Leitura Sobre a Vida dos Grandes Homens; Leitura de Música e Canto; Exercícios Ginásticos e Militares; Trabalhos Manuais Apropriados à Idade e [ao] Sexo (GHIRALDELLI JR., 1990, p. 28).

Os exames rigorosos criavam a necessidade de complementação domiciliar, apesar de o horário escolar oficial ser das nove às duas da tarde e ter duração de quatro anos. Era uma escola para as classes médias, ressalta, mas havia escolas noturnas para maiores de 16 anos com tônica na alfabetização e profissionalização. Fica clara a intenção do autor em demonstrar uma organização educacional classista e elitista preocupada em criar as condições que pudessem cumprir o destino do Brasil planejado naqueles dias.

A edição atualizada de 2009 contempla uma gama maior de capítulos, 14 ao todo, mais a bibliografia e os apêndices para onde foram deslocados o Manifesto dos Pioneiros da Educação Nova, de 1932, e o Manifesto dos Educadores Mais uma Vez Convocados. Outros dois manifestos contemplados na primeira versão não aparecem nesta última. Desaparecem, também, as indicações de leitura complementar e os exercícios propostos ao final de cada capítulo. Da bibliografia, foram excluídos 
os autores Louis Althusser, Tristão de Athaíde, Octavio Ianni, Ivan Illich, Francisco Weffort, Miriam Jorge Warde, Edgard Carone, Barbara Freitag e Gaudêncio Frigotto. Entre as inclusões, temos Pierre Bourdieu e Jean-Claude Passeron, José Arthur Gianotti, Mario Manacorda, Marilena Chauí, Ernest Cassirer, Eliane Marta Teixeira Lopes e Ana Maria Galvão, Carl Rogers, dentre outros.

$\mathrm{Na}$ "Introdução", de duas páginas e meia, o autor destaca três tópicos: 1) Educação e escola; 2) História e historiografia da educação; e 3) Este livro. No primeiro tópico, pegando a etimologia do termo "educação", entende que a dupla derivação do termo conduz aos dois grandes caminhos da filosofia da educação: 1) educação é dirigir exteriormente; 2) educação é incentivar o aprendiz a forjar as suas próprias regras. Prossegue com a etimologia da palavra "escola", para chegar às acepções presentes condensadas na ideia de espaço de instrução e/ou lazer destinado às crianças e aos jovens. No item "História e a historiografia", o autor opera um deslocamento importante com relação à versão primeira, associando ambas à educação. Informa o autor, na introdução:

A história e a historiografia da educação fazem o mesmo que a história, mas escolhem como foco de atenção campos especiais da atuação humana. Basicamente, como os pensadores Emile Durkheim (1857-1917) e Wilhelm Dilthey (1833-1911) nos ensinaram, dois grandes campos: o da política educacional e o das ideias pedagógicas (GHIRALDELLI JR., 2009, p. 14, grifos do autor).

A linha de abordagem permanece operando, basicamente, nesses dois sentidos: política institucional e ideias pedagógicas, repetindo os campos de pertencimento dessas abordagens, o primeiro agregando as intenções de partidos, governos e organizações diversas; o segundo indo do mais amplo debate filosófico às mais específicas discussões sobre a metodologia da relação ensino-aprendizagem. O parágrafo seguinte dedica-se a explicar o que o historiador da educação pode tomar como fonte de investigação no que diz respeito aos textos ou materiais iconográficos e similares, tais como, "jornais, periódicos oficiais, livros científicos e didáticos, revistas comuns e especializadas, manifestos de educadores, filmes de época, músicas, fotos, cartilhas, jornais de grêmios estudantis, jornais de sindicatos de professores, entrevistas com educadores, etc." (GHIRALDELLI JR., 2009, p. 14). Os historiadores que trabalham com o chamado "material primário", em geral, recorrem aos arquivos, às bibliotecas e aos museus, e mais "à internet e às suas memórias" (GHIRALDELLI JR., 2009, p. 14). E assim o autor conclui:

A maioria dos bons livros de história da educação são os que possuem, de uma maneira harmônica, informações desse "material primário" articuladas com informações colhidas criticamente do chamado "material secundário". Este, por sua vez, se constitui nos livros de história da educação. Os que são contemporâneos e os que já saíram de circulação e que, às vezes, já estão se confundindo com o que seria o "material primário" (2009, p. 15). 
Ele encerra a introdução afirmando ser o livro destinado "àquele que deseja se informar para então prosseguir seus estudos” (2009, p. 15). Não há, como na versão anterior, destinação focada nos professores em formação ou em exercício. Esse desligamento de uma coleção que o referende, esse percurso independente que o livro inicia nessa versão atualizada, quando observados levando-se em conta a aposta do investimento editorial, podem sugerir a identificação de um lastro de potenciais leitores em demanda crescente na temática do livro em questão. As reiteradas edições da nova versão nessas duas últimas décadas dão suporte à hipótese e instigam outras questões.

Embora Philippe Ariès não conste de sua bibliografia, o capítulo 1, "Infância, escola e filosofias da educação", abre-se com a emergência histórica da noção de infância nas sociedades do Ocidente. Afirma que a escola, nessas sociedades, teria surgido para permitir a infância das crianças de outro modo impossível. Debate sobre uma infância negativa e outra positiva, ambas creditadas a Descartes e a Rousseau, respectivamente. Novamente, articula o debate em torno da construção filosófica da educação, opondo dois modos de concebê-la forjados na Era Moderna. O instituído por Descartes - um iluminista, segundo o autor - realiza-se na imposição exercida pelo meio sobre o indivíduo, ou "de fora para dentro", e contrasta com outra, romântica, feita para aflorar a criatividade e a pureza do indivíduo "de dentro para fora", como reconhece em Rousseau. Recorrendo à prática dialógica dos filósofos, ele aponta as perguntas a partir das quais o capítulo se desenvolve: "Como essas filosofias da educação modernas - iluminista e romântica - se consubstanciam em pedagogias, no sentido mais estrito desse termo?", "Que tradições pedagógicas estão assentadas nas filosofias da educação das matrizes cartesiana e rousseauniana?". Responde com a interpretação de duas gravuras com representações de ensino. A primeira, onde se lê "quem poupa a vara odeia a criança", estaria representando a pedagogia tradicional, cartesiana; na segunda, intitulada "a professora republicana", rousseauniana, estaria representada a pedagogia nova: a imagem da professora contempla a ambiguidade da mãe e da moça sensual. Ambas as figuras seriam, para o autor, versões populares da pedagogia moderna, expressando maneiras de enraizamento daqueles fundamentos na tradição escolar vigente nos dias de hoje.

No capítulo 2, o autor trata da educação no Brasil Colônia e Império condensadas em seis páginas e meia. Ele inicia o capítulo estabelecendo os marcos temporais dos respectivos períodos: o Período Colonial começa em 1500 e vai até 1822, da chegada das caravelas à declaração de independência, afirma na página 24 . Divide a educação desse período em três etapas: 1) a do predomínio dos jesuítas; 2) a das reformas do Marquês de Pombal, em 1759; e 3) a do intervalo entre a chegada da 
Corte Portuguesa e a independência. Sobre os jesuítas, destaca Manoel da Nóbrega e o pioneirismo de seu trabalho (GHIRALDELLI JR., 2009, p. 25). Acerca do conjunto das ações dos jesuítas, informa:

Aos jesuítas coube, praticamente, o monopólio do ensino escolar no Brasil durante um tempo razoável. Algo em torno de duzentos anos. Durante esse tempo, eles fundaram vários colégios com vistas à formação de religiosos. Ainda que os filhos da elite da colônia não quisessem, todos eles, se tornar padres, tinham de se submeter a tal ensino. Eram os únicos colégios existentes (GHIRALDELLI JR., 2009, p. 25).

Salientando o papel da bula Ratio Studiorum, o autor sintetiza o conjunto de saberes praticados nas escolas jesuíticas com vistas à formação integral do homem cristão. Sob os jesuítas, na prática, o ensino das primeiras letras ficou a cargo das famílias, sendo a especialidade dos membros dessa companhia os colégios para jovens, e não a escola elementar (GHIRALDELLI JR., 2009, p. 26). O prestígio da ordem entre a elite brasileira teria advindo dos colégios mantidos por aquela e para os quais se destinavam os filhos desta.

Sobre as reformas pombalinas, afirma adiante:

Ainda que tais medidas tenham desarticulado o incipiente, mas único, sistema de educação, esse período foi rico na formação de intelectuais importantes em nosso país. Eles continuaram, como antes, a concluir seus estudos na Europa, mas agora sob a influência do Iluminismo (GHIRALDELLI JR., 2009, p. 27).

Na sequência, contextualiza as reformas pombalinas no iluminismo, sem tocar no despotismo esclarecido, atribuindo a Pombal o início do ensino público voltado à cidadania e ao preparo de pessoas com "independência de pensamento e discurso" (GHIRALDELLI JR., 2009, p. 27). Seguem-se à expulsão dos jesuítas, as aulas régias responsáveis pelo desaparecimento, no Brasil, do curso de humanidades. Somente nesse momento menciona os professores do período imperial, responsáveis pela montagem da escola, os quais recebiam seus pagamentos do governo. Conclui afirmando que o iluminismo teria interrompido a cultura de verniz dos cursos de humanidades voltados à utilidade.

Sobre a educação no Império, enumera descritivamente as iniciativas desde D. João VI, a Constituição de 1824, a Lei de 1827, a criação do Colégio Pedro II. Destaca o método lancaster de ensino e a tensão entre os ideários positivista e humanista na pedagogia, concluindo com a reforma Leôncio de Carvalho, que abre a liberdade de ensino para quem quisesse lecionar. No seu modo de entender o Império, este tornou o ensino brasileiro dos cursos secundários menos um projeto educacional público e mais um sistema de exames que perdura até hoje quando se pensa o vestibular. 
O capítulo 3 da nova versão corresponde ao capítulo 1 da antiga edição. Ele foi bastante reduzido, ficando restrito a quatro páginas, mas manteve a linha de pensamento centrada no contraste de dois momentos da educação na Primeira República, diferenciados pelo entusiasmo e pela educação de um grupo e o otimismo pedagógico de outro. Contudo, a problematização das ideias pedagógicas em disputas, tal como aparece na primeira versão, ficou bastante reduzida. Sinteticamente, apresenta a tensão entre pedagogia tradicional e pedagogia nova, polarizando o debate entre Johann Friedrich Herbart e John Dewey. A ação do que mantém intitulado de "pedagogia libertária" também aparece, aqui, reduzida e minimizada enquanto iniciativa dos movimentos sociais, quando comparada à primeira versão. Reconfigurada enquanto disposição individualizada de alguns professores, expressa-se por iniciativas dispersas pelo território nacional inspiradas na pedagogia do espanhol Francisco Ferrer y Guardia.

Observa-se, ainda, que nesse capítulo foram subsumidos os debates educacionais e a atuação da $\mathrm{ABE}$, sendo mantidas, contudo, as reformas estaduais do sistema de ensino dos anos 1920 de Anísio Teixeira (Bahia), Lourenço Filho (São Paulo) e Fernando de Azevedo (Distrito Federal) como frutos de um otimismo pedagógico que não se explica para além da iniciativa desses jovens intelectuais. Termina o capítulo com as mudanças ocorridas em São Paulo. Aqui, o autor manteve o texto da versão anterior, cujo subtítulo era "A organização escolar".

\section{Considerações provisórias}

Alguns aspectos pertinentes aos debates em curso no campo da história da educação são trazidos à tona na leitura desses manuais, por oportunizarem reflexão acerca de modalidades diversas de pertencimento, apropriação e legitimação de saberes, práticas de escrita, circulação de conhecimentos produzidos e políticas editoriais. Apontamos alguns destaques decorrentes desse primeiro empenho investigativo sobre o manual em pauta. Primeiro, a manutenção da tradicional abordagem da história da educação na perspectiva que privilegia o estudo da história das ideias pedagógicas, próxima à filosofia. Modelo instituinte da conformação da história da educação enquanto disciplina escolar no início do século XX, esse traço, atenuado na versão recente, cede à maior visibilidade dada ao contexto histórico, mas enquanto meio que possibilita a produção das próprias ideias pedagógicas.

O segundo destaque é a amenização do tom marxista perceptível no apagamento dos movimentos sociais enquanto ator social, valendo para as iniciativas intelectuais relacionadas aos movimentos sindicais, às organizações sociais diversas ou à $\mathrm{ABE}$. $\mathrm{O}$ sentido de luta de classes, empreendido pelo autor às ações citadas na 
primeira versão, é substituído por iniciativas individuais ilustres, pelas atuações dos governos federal e do estado de São Paulo. Mantém o significado do caráter modelar da reforma paulista para o restante do país nos empreendimentos encampados desta pelo governo federal, mas como resultado da iniciativa de um ilustre, e não mais como expressão de ações simultâneas propiciadas por um debate coletivo travado em diferentes espaços.

O terceiro destaque é o silêncio quanto ao largo debate que contrapõe as iniciativas educacionais do Império e da República que a historiografia recente do campo tem problematizado. Ainda que a versão atual do livro dedique seis páginas e meia aos períodos do Brasil Colônia e Império, enquanto a versão anterior iniciava com a Primeira República, o autor não contempla nessas páginas os conhecimentos produzidos no campo acerca das iniciativas educacionais no século XIX e o debate sobre as reformas pombalinas, por exemplo. O eixo sobre o qual assenta o debate, a sustentação desses períodos, replica conhecimentos e concepções ora colocados sob revisão pela historiografia, sendo problematizados em pesquisas cuja repercussão já é ampla e difunde-se a cada dia no campo da história da educação.

Em quarto, é preciso considerar os compromissos e interesses do autor ao movimentar um campo em disputa, imprimindo-lhe uma feição, justificando a permanência e a atualização do texto quando este é associado a determinada tradição de escrita da história da educação da qual esse autor é representante. Entendida como um conjunto de práticas carregado por um sistema de valores moldando o campo disciplinar, essa tradição perpetua-se na reiterada edição desse manual.

O quinto aspecto é a diluição do público-alvo do livro. Enquanto a primeira versão destinava-se aos professores em formação e em exercício, a segunda abre-se àqueles desejosos de "informar-se" e prosseguir nos estudos. A amplitude pretendida por esse novo projeto editorial, contudo, não desconfigura a finalidade do manual, mas traz para o campo da história da educação o problema da circulação mais ampliada da obra em razão da reiteração dos saberes que oferece. Levando em conta as tensões criadas pelo jogo em curso na malha institucional, onde está em disputa a consolidação de saberes, forçoso é pensar, como diz Revel, os aspectos específicos de cada campo, levando em conta as contribuições desse manual para o debate corrente acerca do manejo que consolida e reproduz saberes nessa área e como isso reverbera na composição da identidade da história da educação.

Sexto, e ainda com Revel, se a história é um saber que se legitima à medida que se difunde, então é importante atentar para o fato de o livro constar da bibliografia do programa de vários cursos de formação de professores. Pondo em discussão os modos como as disciplinas constituem-se em dispositivos de controle e como esse ensino responde pela formação de docentes enquanto sujeitos históricos 
com finalidades reprodutivas no sistema escolar, torna-se necessário ponderar qual o papel que a história da educação cumpre nos programas dos cursos de formação de professores. Isso implica pensar no perfil dos profissionais docentes matizado por fundamentos que, embora observem a existência do movimento do pensamento e das ideias aí constituídas - elemento de todo modo fundamental na percepção da história como vir a ser -, deixam-no como que movido pela razão pura ou por uma lei natural forjada nesse fluxo de ideias encadeadas por uma sequência precisa de localização de precedente e sucessivo.

Não levar em conta a forma como os marcadores de uma disciplina doutrinam é desconsiderar seu papel formador mais sutil e perspicaz. Não observar quais os marcadores eleitos por uma época para cumprir essa função é manter o alheamento quanto aos procedimentos de escolha e eleição desses marcadores. Não problematizá-los é perpetuar a ilusão quanto ao natural percurso de processos deliberados conforme intenções precisas e projetos estritos em atuação nos procedimentos de escrita autoral, no campo disciplinar e no mercado editorial.

Tabela 1 - Organização do livro na edição de 1990 e na edição de 2009

\begin{tabular}{|c|c|c|}
\hline & História da educação (1990) & História da educação brasileira. 4. ed. (2009) \\
\hline Entrada & $\begin{array}{l}\text { Apresentação da coleção } \\
\text { Apresentação }\end{array}$ & Introdução \\
\hline Capítulo 1/1 & $\begin{array}{l}\text { A Primeira República } \\
\text { 1. Do "entusiasmo pela educação" ao } \\
\text { "otimismo pedagógico" } \\
\text { 2. Os conflitos pedagógicos } \\
\text { 3. A organização escolar } \\
\text { - Leituras complementares e de } \\
\quad \text { aprofundamento } \\
\text { - Exercícios }\end{array}$ & Infância, escola e filosofias da educação \\
\hline Capítulo II/2 & $\begin{array}{l}\text { A Segunda República } \\
\text { 1. Reflexões didático-pedagógicas e política } \\
\text { educacional nos confrontos ideológicos } \\
\text { dos anos } 30 \\
\text { - Leituras complementares e de } \\
\text { aprofundamento } \\
\text { - Exercícios } \\
\text { Apêndice: "O manifesto dos Pioneiros da } \\
\text { Educação Nova (1932)" }\end{array}$ & $\begin{array}{l}\text { Educação e Pedagogia na Colônia e no } \\
\text { Império } \\
\text { 1. Jesuítas e Pombal } \\
\text { 2. As escolas do Império }\end{array}$ \\
\hline Capítulo III/3 & $\begin{array}{l}\text { O Estado Novo } \\
\text { 1. Educação na Constituição de } 1937 \\
\text { 2. As Leis Orgânicas do Ensino } \\
\text { 3. Os educadores liberais e a Ditadura } \\
\text { - Leituras complementares e de } \\
\quad \text { aprofundamento } \\
\text { - Exercícios }\end{array}$ & $\begin{array}{l}\text { Ensino, legislação e escolas na "República } \\
\text { Velha" } \\
\text { 1. O entusiasmo pela educação e o otimismo } \\
\quad \text { pedagógico } \\
\text { 2. A atuação do Governo Federal } \\
\text { 3. Alguns dados do estado de São Paulo }\end{array}$ \\
\hline
\end{tabular}




\begin{tabular}{|c|c|c|}
\hline Capítulo IV/4 & $\begin{array}{l}\text { A Quarta República } \\
\text { 1. Educação e classes populares na } \\
\text { redemocratização (1945-1947) } \\
\text { 2. A tramitação do Projeto da Lei de } \\
\text { Diretrizes e Bases da Educação Nacional } \\
\text { e a luta pela escola pública } \\
\text { 3. Os movimentos de educação popular e a } \\
\text { pedagogia libertadora } \\
\text { 4. A Pedagogia Nova } 40 \text { anos depois do } \\
\text { Manifesto dos Pioneiros } \\
\text { 5. A política educacional dos governos } \\
\text { populistas } \\
\text { - Leituras complementares e de } \\
\text { aprofundamento } \\
\text { - Exercícios } \\
\text { Apêndice: "Manifesto dos Educadores } \\
\text { Mais Uma Vez Convocados" (1959) }\end{array}$ & $\begin{array}{l}\text { Reformas educacionais e ideários } \\
\text { pedagógicos dos inícios dos anos 30; a } \\
\text { educação na Constituinte de } 1934 \\
\text { 1. Reforma Francisco Campos } \\
\text { 2. A Associação Brasileira de Educação } \\
\text { (ABE) } \\
\text { 3. O Manifesto dos Pioneiros da Educação } \\
\text { Nova } \\
\text { 4. Quem eram os signatários do Manifesto } \\
\text { de } 1932 \\
\text { 5. Os "cardeais do movimento renovador" } \\
\text { 6. As propostas pedagógicas dos anos trinta: } \\
\text { o ideário liberal } \\
\text { 7. Ideário católico } \\
\text { 8. Ideário integralista } \\
\text { 9. Ideário comunista } \\
\text { 10. A educação na Constituinte de 1933-34 }\end{array}$ \\
\hline Capítulo V/5 & $\begin{array}{l}\text { 1. O Golpe de } 31 \text { de março de } 1964 \text { e as Leis } \\
5.540 / 68 \text { e } 5692 / 71 \\
\text { 2. A reforma universitária e a } \\
\text { institucionalização do ensino } \\
\text { profissionalizante no } 2^{\circ} \text { grau } \\
\text { 3. O fracasso da política educacional da } \\
\text { Ditadura } \\
\text { - Leituras complementares e de } \\
\text { aprofundamento } \\
\text { - Exercícios }\end{array}$ & $\begin{array}{l}\text { A organização do ensino legada pelo Estado } \\
\text { Novo } \\
\text { 1. A Constituinte de } 1937 \\
\text { 2. As Leis Orgânicas do Ensino }\end{array}$ \\
\hline Capítulo VI/6 & $\begin{array}{l}\text { A Ditadura Militar (II) e o advento da Nova } \\
\text { República } \\
\text { 1. A literatura pedagógica durante a Ditadura } \\
\text { Militar } \\
\text { 2. Os partidos políticos progressistas e as } \\
\text { questões educacionais nos últimos anos } \\
\text { da Ditadura Militar (1979-85) } \\
\text { 3. A problemática educacional e pedagógica } \\
\text { no momento do advento da Nova } \\
\text { República } \\
\text { - Leituras complementares e de } \\
\text { aprofundamento } \\
\text { - Exercícios } \\
\text { Apêndice: "Carta de Goiânia" (1986) } \\
\text { "Manifesto aos Participantes da III } \\
\text { Conferência Brasileira de Educação" } \\
\text { (1984) }\end{array}$ & $\begin{array}{l}\text { Lutas em torno da primeira LDBN e } \\
\text { movimentos populares em educação } \\
\text { 1. Educação pública versus escola particular } \\
\text { e a primeira LDBN } \\
\text { 2. A política educacional } \\
\text { 3. Paulo Freire: pedagogia made in Brazil }\end{array}$ \\
\hline Capítulo 7 & & $\begin{array}{l}\text { Ideário autoritário e leis da educação sob a } \\
\text { Ditadura Militar } \\
\text { 1. As ideias sobre educação da Ditadura } \\
\quad \text { Militar } \\
\text { 2. A reforma universitária } \\
\text { 3. A LDBN 5692/71 }\end{array}$ \\
\hline
\end{tabular}




\begin{tabular}{|c|c|}
\hline Capítulo 8 & $\begin{array}{l}\text { Leituras em educação nas décadas de } 1970 \\
\text { e } 1980 \\
\text { 1. O piagetianismo de Lauro de Oliveira Lima } \\
\text { e as "teorias de instrução" } \\
\text { 2. Não diretivismo de Karl Rogers e a escola } \\
\text { "Summerhill" } \\
\text { 3. As conversas de Rubem Alves } \\
\text { 4. Em torno da "Escola Nova Popular" } \\
\text { 5. A sociologia crítica da educação } \\
\text { 6. Os teóricos da desescolarização } \\
\text { 7. Maurício Tragtenberg e a } \\
\text { desburocratização da escola } \\
\text { 8. Dermeval Saviani e o marxismo na } \\
\text { educação } \\
\text { 9. Pragmatismo, positivismo sociológico e a } \\
\text { filosofia analítica } \\
\text { 10. Professores com acesso à mídia } \\
\text { analisam a "barbárie na universidade" }\end{array}$ \\
\hline Capítulo 9 & $\begin{array}{l}\text { A democracia: da política educacional dos } \\
\text { partidos e do governo federal à nova LDBN } \\
\text { 9.394/96 } \\
\text { 1. Os partidos políticos e a educação } \\
\text { 2. O governo federal e a educação brasileira } \\
\text { na democracia entre } 1985 \text { e } 1992 \\
\text { 3. A Lei de Diretrizes e Bases da Educação } \\
\text { Nacional - LDBN 9.394/96 }\end{array}$ \\
\hline Capítulo 10 & $\begin{array}{l}\text { Rumos da literatura pedagógica brasileira no } \\
\text { final do século } \\
\text { 1. A sociologia e a teoria do currículo } \\
\text { 2.Filosofia da educação, psicopedagogia e } \\
\text { teorias educacionais } \\
\text { 3. Historiografia da educação }\end{array}$ \\
\hline Capítulo 11 & Plano Nacional de Educação (1998) \\
\hline Capítulo 12 & $\begin{array}{l}\text { Os sistemas de avaliação do governo } \\
\text { Fernando Henrique Cardoso }\end{array}$ \\
\hline Capítulo 13 & $\begin{array}{l}\text { O professor do ensino básico no Brasil do } \\
\text { final do século XX }\end{array}$ \\
\hline Capítulo 14 & $\begin{array}{l}\text { As teorias pedagógico-didáticas no } \\
\text { Brasil entre os séculos } X X \text { e o XXI - uma } \\
\text { observação Pessoal }\end{array}$ \\
\hline Bibliografia & $\begin{array}{l}\text { Algumas exclusões: ALTHUSSER, L.; } \\
\text { ATHAÍDE, T.; IANNI, O.; ILLICH, I.; } \\
\text { WEFFORT, F.; WARDE, M. J.; FREITAG, B.; } \\
\text { FRIGOTTO, G. } \\
\text { Algumas liclusões: BOURDIEU; PASSERON; } \\
\text { GIANOTTI, J.A.; MANACORDA, M.; } \\
\text { ROGERS, C. } \\
\text { LOPES, E. M. T.; GALVÃO, A. M. }\end{array}$ \\
\hline Apêndice & $\begin{array}{l}\text { Manifesto dos Pioneiros da Educação Nova } \\
\text { de } 1932 \\
\text { Manifesto dos Educadores Mais uma Vez } \\
\text { Convocados }\end{array}$ \\
\hline
\end{tabular}




\section{Manuals of history of education: from production of the knowledge until dissemination of the scholarly knowledge (1990-2009)}

\section{Abstract}

This work arguments the repeated publication of a handbook of Brazilian History Education. We compare the first edition (1990), titled History of Education, with the latest version, reprinted for the fourth time in 2009, published under the title History of Brazilian Education, from Paul Ghiraldelli Jr. The time frame observes two editorial moments of historiographical exercise, which are constituted by the documents about the debate on the prevalence of knowledge in dispute in the field of history of education. We aim to reflect on the following questions, in light of the addresses for this production and its specific conditions of writing/rewriting: the institutional mesh where it is signed/ inscribed, the field of knowledge that legitimizes; the erasure of the representations in dispute and the meanings of circulation of this work to the field of history of education.

Keywords: History of education. Paulo Ghiraldelli Jr. Historiography.

\section{Notas}

1 Uma versão preliminar deste trabalho foi apresentada no IX Congresso Luso-Brasileiro de História da Educação, em Lisboa - PT, 2012.

${ }^{2}$ Segundo informações da editora Cortez, as duas versões do livro, considerando apenas as publicações feitas neste século, tiveram as seguintes edições, com as respectivas tiragens: História da educação: $2^{a}$ edição revista/5 ${ }^{\mathrm{a}}$ reimpressão: 2001 - tiragem: 2.000; $2^{\mathrm{a}}$ edição revista/6 $6^{\mathrm{a}}$ reimpressão: 2002 - tiragem: 3.000; $2^{\mathrm{a}}$ edição revista/7 ${ }^{\mathrm{a}}$ reimpressão: 2003 - tiragem: 2.000*; História da educação brasileira: $1^{\mathrm{a}}$ edição - 2006 - tiragem: 2.000; $2^{\mathrm{a}}$ edição - 2006 - tiragem: 2.000; $3^{\mathrm{a}}$ edição - 2008 - tiragem: 3.000; $4^{\mathrm{a}}$ edição - 2009 tiragem: 2.000; $4^{\mathrm{a}}$ edição complementar - 2010 - tiragem: $2.000 ; 4^{\mathrm{a}}$ edição/ $1^{\mathrm{a}}$ reimpressão - 2011 - tiragem: 2.000. Das edições anteriores a essa primeira versão do livro, publicadas na última década do século XX, a editora não forneceu informações.

3 GHIRALDELLI JR., Paulo. História da educação. São Paulo: Cortez, 1990; História da educação brasileira. 4. ed. São Paulo: Cortez, 2009.

4 Esses não são os únicos títulos do autor na editora; há outros dois: Infância, educação e neoliberalismo e Educação e razão histórica, ambos publicados na década de 1990. O autor tem, ainda, vários livros publicados por outras grandes editoras brasileiras, como PD\&A, Ática e Brasiliense.

5 As edições tiveram, em geral, dois mil exemplares. Apenas a segunda edição da primeira versão e a terceira edição da versão mais recente tiveram tiragem de três mil exemplares cada uma, conforme informação obtida da própria editora.

${ }^{6}$ Disponível em: <http://ghiraldelli.pro.br/>. 


\section{Referências}

ASCOLANI, Adrián; GONDRA, José Gonçalves. Pela classe, pelo livro: a fundação de uma História da Educação para professores, no Brasil e na Argentina. In: VIDAL, Diana G.; ASCOLANI, Adrián (Orgs.). Reformas educativas no Brasil e na Argentina: ensaios de história comparada da educação (1820 -1980). São Paulo: Cortez, 2009. p. 43-86.

BITTENCOURT, Circe Maria Fernandes. Ensino de história: fundamentos e métodos. São Paulo: Cortez, 2005.

CARVALHO, Marta Maria Chagas de. A configuração da historiografia educacional brasileira. In: FREITAS, Marcos Cezar (Org.). Historiografia brasileira em perspectiva. São Paulo: Contexto, 2010. p. 329-353.

FOUCAULT, M. A ordem do discurso. 20. ed. São Paulo: Loyola, 2010.

GHIRALDELLI JR., Paulo. História da educação. São Paulo: Cortez, 1990.

. História da educação brasileira. 4. ed. São Paulo: Cortez, 2009.

GONDRA, José; SOOMA SILVA, José Cláudio (Orgs.). História da educação na América Latina: ensinar \& escrever. Rio de Janeiro: Eduerj, 2011.

MARTÍNEZ V., Emma D. De la práctica cotidiana a la reflexión necesaria en historia de la educación. In: GONDRA, José; SOOMA SILVA, José Cláudio (Orgs.). História da educação na América Latina: ensinar \& escrever. Rio de Janeiro: Eduerj, 2011. p. 167-195.

REVEL, Jacques. História e historiografia: exercícios críticos. Curitiba: Ed. da UFPR, 2010.

WARDE, Miriam J. Contribuições da história para a educação. Em Aberto, Brasília, ano 9, n. 47, p. 3-11, 1990.

Brincando nos campos do senhor: anotações para uma história da formação dos professores e do ensino na história da educação no Brasil (p. 305-335). In: CARVALHO, Marta M. C.; GATTI JÚNIOR, Décio (Orgs.). O ensino de história da educação. Vitória: SBHE/UFES, 2011. p. 305-335. 